\title{
Multi-scale data on intertidal macrobenthic biodiversity and environmental features in three New Zealand harbours
}

\author{
Casper Kraan ${ }^{1,2, a}$, Barry L. Greenfield ${ }^{3}$, and Simon F. Thrush ${ }^{4}$ \\ ${ }^{1}$ Helmholtz Institute for Functional Marine Biodiversity at the University of Oldenburg, \\ Ammerländer Heerstraße 231, 23129 Oldenburg, Germany \\ ${ }^{2}$ Department of Functional Ecology, Alfred Wegener Institute, Helmholtz Centre for Polar and Marine \\ Research, Am Handelshafen 12, 27570 Bremerhaven, Germany \\ ${ }^{3}$ National Institute of Water and Atmospheric Research, P.O. Box 11-115, Hamilton 3216, New Zealand \\ ${ }^{4}$ Institute of Marine Science, University of Auckland, Private Bag 92019, Auckland 1142, New Zealand \\ ${ }^{a}$ currently at: Thünen Institute of Sea Fisheries, Herwigstraße 31, 27572 Bremerhaven, Germany
}

Correspondence: Casper Kraan (casper.kraan@thuenen.de)

Received: 27 August 2019 - Discussion started: 16 September 2019

Revised: 19 January 2020 - Accepted: 21 January 2020 - Published: 10 February 2020

\begin{abstract}
Understanding how the plants and animals that live in the sea floor vary in their spatial patterns of diversity and abundance is fundamental to gaining insight into the role of biodiversity in maintaining ecosystem functioning in coastal ecosystems, as well as advancing the modelling of species distributions under realistic assumptions. Yet, it is virtually unknown how the relationships between abundance patterns and different biotic and environmental processes change depending on spatial scales, which is mainly due to a lack of data. Within the project Spatial Organization of Species Distributions: Hierarchical and Scale-Dependent Patterns and Processes in Coastal Seascapes at the National Institute for Water and Atmospheric Research (NIWA) in New Zealand we collected multi-scale and high-resolution data on macrobenthic biodiversity. We found 146 species dominated by bivalves, polychaetes, and crustaceans $(>500 \mu \mathrm{m})$ that live hidden in marine sandflats and collected point measurements of important environmental variables (sediment grain-size distributions, chlorophyll $a$ concentration, organic content, and visible sandflat parameters) in three large intertidal harbours (Kaipara, Tauranga, and Manukau). In each harbour we sampled 400 points for macrobenthic community composition and abundances, as well as the full set of environmental variables. Using an elaborate sampling design, we were able to cover scales from $30 \mathrm{~cm}$ to a maximal extent of $1 \mathrm{~km}$. All data and extensive metadata are available from the data publisher PANGAEA via the persistent identifier https://doi.org/10.1594/PANGAEA.903448 (Kraan et al., 2019).
\end{abstract}

Understanding how the plants and animals that live in the sea floor vary in their spatial patterns of diversity, biomass, and abundance is fundamental to gaining insight into the role of biodiversity in maintaining ecosystem functioning in coastal ecosystems, as well as advancing the modelling of species distributions under realistic assumptions. Yet, it is virtually unknown how the relationships between abundance patterns and different biotic and environmental processes change de- pending on spatial scales (e.g. Lohrer et al., 2015; Kraan et al., 2015).

Most broad-scale research on mapping species distributions ignores spatial patterns (Kraan et al., 2010), scaledependent variability (Kraan et al., 2015), and biotic interactions (Dormann et al., 2018), rendering these topics a main frontier in ecology (Araújo and Luoto, 2007). Moreover, twisting these often separate lines of research together requires the availability of data to support such research. At present, data that allow for bridging the gap between small- 


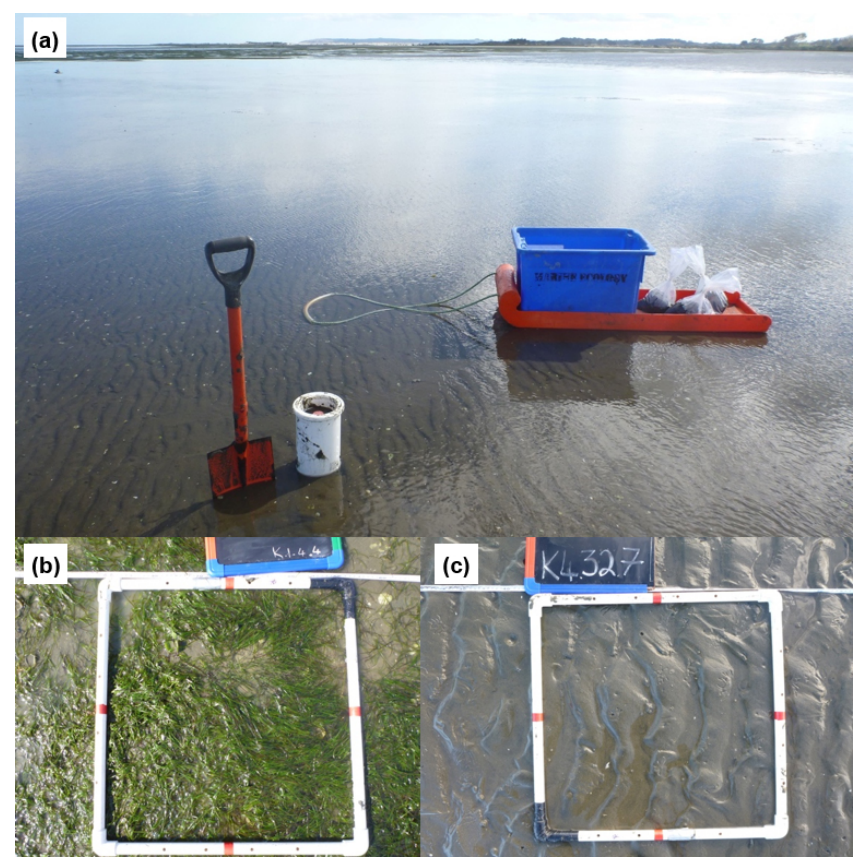

Figure 1. (a) Example of a sampling area during low tide and the low-tech gear used for sampling. Examples of (b) a high-density seagrass sampling point and (c) a sandy sampling point (photos: Casper Kraan).

scale and landscape-scale ecological research, enabling a full inference of patterns and processes from the individual to the landscape scale across environmental gradients, are scarce.

The research project Spatial Organization of Species Distributions: Hierarchical and Scale-Dependent Patterns and Processes in Coastal Seascapes at the National Institute for Water and Atmospheric Research (NIWA) in New Zealand aimed to assess scale-dependent variation in species distributions across environmental gradients in estuarine communities dominated by bivalves, polychaetes, and crustaceans that live hidden in marine sandflats. By employing an elaborate sampling scheme, we covered a large number of different spatial scales with enough replicate samples within each scale to allow for explicit spatial analysis and warrant statistical power during analysis (see Kraan et al., 2015; Greenfield et al., 2016). This efficient sampling design allowed us to map intertidal macrobenthic fauna from the scale of a few centimetres to a maximal extent of $1 \mathrm{~km}$. We focussed on macrobenthos (organisms $>500 \mu \mathrm{m}$ ) due to their role in ecosystem functioning (e.g. Thrush et al., 2017), their ability to serve as sentinels for change (e.g. Hewitt and Thrush, 2009; Kraan et al., 2009), and the relative ease of collecting samples (Fig. 1). To increase the generality of our field study, we performed this sampling along an environmental gradient from the mangroves to the lower end of the intertidal zone in three large intertidal harbours (Manukau, Kaipara, and Tauranga harbours in the North Island, New Zealand).
Given the scarcity of large-scale high-resolution biodiversity data identified to the lowest taxonomic level possible, as well as associated point measurements of environmental features like sediment grain-size parameters, chlorophyll $a$ concentration, organic content, and visible sandflat parameters, such as the coverage of seagrass or shell hash (broken shell fragments), we publish these one-of-a-kind data (see Kraan et al., 2019) here so that they can serve as key data to advance and support future multi-scale biodiversity studies.

\section{Material and methods}

\subsection{Fieldwork}

Sampling of macrobenthic fauna and environmental variables was conducted during austral summer 2012 in Kaipara, Manukau, and Tauranga harbours, North Island, New Zealand (Table 1). Physical descriptions of each of these areas can be sourced from a large number of publications by Simon F. Thrush and co-workers (e.g. Thrush et al., 2003). In each harbour we took 400 cores $(13 \mathrm{~cm}$ diameter, $20 \mathrm{~cm}$ deep) on a predetermined grid (four $1000 \mathrm{~m}$ transects, spaced at $100 \mathrm{~m})$ on foot during low tide $(n=3 \cdot 400 ; 1200$ in total), thereby covering the area from the high- to low-water mark (Fig. 1 for an illustration). Sampling points along transects were spaced at distances of $30 \mathrm{~cm}, 1 \mathrm{~m}, 5 \mathrm{~m}, 10 \mathrm{~m}, 30 \mathrm{~m}$, $50 \mathrm{~m}, 100 \mathrm{~m}, 500 \mathrm{~m}$, and $1000 \mathrm{~m}$ (see Fig. 1 in Kraan et al., 2015), located by using a measuring tape and handheld GPS. Given the close proximity of sampling locations we provide sampling coordinates in NZTM (New Zealand Transverse Mercator; Geodetic CRS: NZGD2000; unit: metres) at the data publisher PANGAEA (Kraan et al., 2019). Cores were sieved in the field $(500 \mu \mathrm{m}$ mesh) and the residue preserved with $70 \%$ isopropyl alcohol.

Prior to destructive sampling, we took a photograph of $50 \mathrm{~cm} \times 50 \mathrm{~cm}$ at each sampling point $(n=960)$ to assess the coverage of seagrass (Zostera muelleri), bare sand, and shell hash. In addition, at each point $(n=960)$, we pooled three surface sediment cores ( $2 \mathrm{~cm}$ diameter, $2 \mathrm{~cm}$ deep) for sediment grain-size analyses (median grain-size and sediment fractions), chlorophyll $a$ measurements, and determination of the organic content of the sediment (Table 1). These samples were stored in the dark on ice immediately after collecting. Note that at the smallest spatial scale, i.e. $30 \mathrm{~cm}$, we took three adjoining benthic cores, but we limited ourselves to taking one photograph and one sediment sample to represent the environmental features for these three locations. This was done to economically manage our time in the field and our financial budget for processing samples, leading to 320 photographs and 320 sediment samples per harbour. See Kraan et al. $(2015,2019)$ or Greenfield et al. (2016) for details. 
Table 1. Regional summary of collected data and their mean values to give an impression of their physical appearance and the macrobenthic benthic biodiversity they harbour.

\begin{tabular}{|c|c|c|c|}
\hline \multirow[t]{2}{*}{ Fieldwork 2012} & \multicolumn{3}{|c|}{ Region } \\
\hline & Manukau & Tauranga & Kaipara \\
\hline Sampling & 4-5 May & 23-25 April & 18-19 April \\
\hline Sediment samples $(n)$ & 320 & 320 & 320 \\
\hline Organic content samples $(n)$ & 320 & 320 & 320 \\
\hline Chlorophyll $a$ samples $(n)$ & 320 & 320 & 320 \\
\hline Visible sandflat parameters ( $n$ photos) & 318 & 319 & 297 \\
\hline Lost photos due to water coverage & m.1.10.9, m.4.39.7 & $\begin{array}{l}\mathrm{k} 1.4 .2, \mathrm{k} 2.19 .4, \mathrm{k} 2.19 .5, \\
\mathrm{k} 2.19 .6, \mathrm{k} 2.19 .7, \mathrm{k} 2.19 .8, \\
\mathrm{k} 2.19 .9, \mathrm{k} 2.19 .10, \mathrm{k} 2.20 .1, \\
\mathrm{k} 2.20 .2, \mathrm{k} 2.20 .3, \mathrm{k} 2.20 .4, \\
\mathrm{k} 2.20 .5, \mathrm{k} 2.20 .6, \mathrm{k} 2.20 .7, \\
\mathrm{k} 2.20 .8, \mathrm{k} 2.20 .9, \mathrm{k} 2.20 .10, \\
\mathrm{k} 4.31 .1, \mathrm{k} 4.31 .2, \mathrm{k} 4.31 .3, \\
\mathrm{k} 4.37 .3, \mathrm{k} 4.38 .10\end{array}$ & $\mathrm{t} 1.8 .5$ \\
\hline Macrobenthos samples $(n)$ & 400 & 399 & 398 \\
\hline Lost macrobenthos samples & & $\mathrm{T} 4.35 .5$ & $\mathrm{~K} 3.24 .3, \mathrm{k} 4.35 .5$ \\
\hline \multicolumn{4}{|l|}{ Results of laboratory work 2012-2014 } \\
\hline Species identified $(n)$ & 109 & 81 & 114 \\
\hline Individuals $(n)$ & 26573 & 25394 & 21846 \\
\hline Median grain size $(\mu \mathrm{m})$ & 166 & 197 & 213 \\
\hline Silt $(\%<63 \mu \mathrm{m})$ & 14 & 5 & 1 \\
\hline Very fine sediments (\% 63-125 $\mu \mathrm{m})$ & 17 & 17 & 6 \\
\hline Fine sediments $(\% 125-250 \mu \mathrm{m})$ & 48 & 44 & 6 \\
\hline Medium sediments (\% 250-500 $\mu \mathrm{m})$ & 18 & 28 & 32 \\
\hline Coarse sediments $(\%>500 \mu \mathrm{m})$ & 3 & 6 & 0.4 \\
\hline Organic content $(\%)$ & 2 & 2 & 0.8 \\
\hline Chlorophyll $a\left(\mathrm{mg} \mathrm{g}^{-1}\right)$ & 23 & 11 & 5 \\
\hline Bare sand cover $(\%)$ & 79 & 73 & 84 \\
\hline Shell hash cover $(\%)$ & 16 & 3 & 2 \\
\hline Seagrass cover $(\%)$ & 5 & 23 & 13 \\
\hline
\end{tabular}

\subsection{Macrobenthic data}

In the laboratory, rose-bengal-stained (2\%) taxa were identified to the lowest practical taxonomic resolution and their abundance assessed. In total we identified 146 species, mostly bivalves, polychaetes, and crustaceans, encompassing 73813 individuals (Table 1; Supplement, Kraan et al., 2019). For bivalves, the longest shell axis was also measured, allowing adults and juveniles to be distinguished, because habitat preferences can differ between adults and juveniles (Kraan et al., 2010, 2013). Size classes were categorized as $<1,1-5,5-10,10-15,15-20,20-25,25-30,30-35,35-40$, and $>40 \mathrm{~mm}$. Each sample was sorted and its taxa identified by Casper Kraan, after which Barry L. Greenfield verified species identifications on each sample (Kraan et al., 2019).

\subsection{Chlorophyll a measurements}

Sediment samples were freeze-dried upon arrival in the laboratory. Prior to freeze-drying, seagrass and bivalves were removed. For measuring, $0.1 \mathrm{~g}$ of sediment was weighed, topped up with $90 \%$ acetone buffer, and centrifuged for $10 \mathrm{~min}$ at $3300 \mathrm{rpm}$. Chlorophyll $a$ and pheophytin concentrations ( $n=960)$ were determined with a fluorometer using standard methods (see Kraan et al., 2015). The first sample was measured on 10 May 2012, and the last sample was measured on 28 June 2012, avoiding degradation of samples over time (see Kraan et al., 2019).

\subsection{Sediment grain-size distributions}

To determine sediment median grain-size and sediment fractions (silt $<63 \mu \mathrm{m}$, very fine $63-125 \mu \mathrm{m}$, fine $125-250 \mu \mathrm{m}$, medium $250-500 \mu \mathrm{m}$, and coarse $>500 \mu \mathrm{m}$ ), sediment grain sizes were measured $(n=960)$, following standard methods for using a Malvern Mastersizer 2000 with a particle range of 0.02-2000 $\mu \mathrm{m}$ (see Kraan et al., 2015). This involved digesting about a teaspoon of sediment by adding $10 \%$ hydrogen 
peroxide to remove organic content from the sediment, leaving it to digest for $7 \mathrm{~d}$, and stirring every couple of days.

\subsection{Organic content of the sediment}

Organic content $(n=960)$ was determined after burning a teaspoon of freeze-dried sediment for $5.5 \mathrm{~h}$ in a furnace at $560^{\circ} \mathrm{C}$, i.e. the loss-on-ignition approach.

\subsection{Visible sandflat parameters}

The coverage of seagrass, shell hash, and bare sand within each photograph $(n=960)$ was estimated based on 75 random points within a photograph using the software CPCe (Kohler and Gill, 2006) (see Kraan et al., 2019).

\section{Data availability}

All data collected during this project, including extensive metadata, are available from the data publisher PANGAEA (Kraan et al., 2019). For convenience, all data are grouped into a parent dataset (https://doi.org/10.1594/PANGAEA.903448; Kraan et al., 2019).

A number of scientific studies have used these data. For example, Kraan et al. (2015) described the cross-scale variation in biodiversity-environment links using Moran's eigenvector mapping (MEM). Greenfield et al. (2016) focussed on the spatial distribution of functional groups to gain insight into the scale dependency of resilience. Thrush et al. (2017) and Douglas et al. (2017) based their experimental set-up on the spatial distribution of functional hot and cold spots to experimentally study the impact of nutrient loading on ecosystem functioning and resilience.

Supplement. The supplement related to this article is available online at: https://doi.org/10.5194/essd-12-293-2020-supplement.

Author contributions. CK and SFT designed the study, and CK and BLG carried it out. CK prepared this paper with contributions and the final approval of all authors.

Competing interests. The authors declare that they have no conflict of interest.

Acknowledgements. We thank Sylvia de Juan, Andres Ospina, Katie Cartner, Kelly Carter, Sarah Hailes, Hazel Needham, Clarisse Niemand, Rachel Harris, and Rebecca GladstoneGallagher for their help during fieldwork and laboratory work.
Financial support. This research has been supported by the Royal Society of New Zealand, Marsden Fund (grant no. NIW1102) and the FP7 People: Marie-Curie Actions (BAYESIANMETAFLATS (grant no. 298380)).

Review statement. This paper was edited by Francois Schmitt and reviewed by Clément Garcia and Olivier Beauchard.

\section{References}

Araújo, M. B. and Luoto, M.: The importance of biotic interactions for modelling species distributions under climate change, Global Ecol. Biogeogr., 16, 743-753, https://doi.org/10.1111/j.14668238.2007.00359.x, 2007.

Dormann, C. F., Bobrowski, M., Dehling, D. M., Harris, D. J., Hartig, F., Lischke, H., Moretti, M., Pagel, J., Pinkert, S., Schleuning, M., Schmidt, S. I., Sheppard, C. S., Steinbauer, M. J., Zeuss, D., and Kraan, C.: Biotic interactions in species distribution modelling: ten questions to guide interpretation and avoid false conclusions, Global Ecol. Biogeogr., 27, 1004-1016, https://doi.org/10.1111/geb.12759, 2018.

Douglas, E. J., Pilditch, C. A., Kraan, C., Schipper, L. A., Lohrer, A. M., and Thrush, S. F.: Macrofaunal functional biodiversity provides resilience to nutrient enrichment in coastal sediments, Ecosystems, 7, 1324-1336, https://doi.org/10.1007/s10021-0170113-4, 2017.

Greenfield, B. L., Kraan, C., Pilditch, C. A., and Thrush, S. F.: Mapping functional groups can provide insight into ecosystem functioning and potential resilience of intertidal sand flats, Mar. Ecol.-Prog. Ser., 548, 1-10, https://doi.org/10.3354/meps11692, 2016.

Hewitt, J. E. and Thrush, S. F.: Reconciling the influence of global climate phenomena on macrofaunal temporal dynamics at a variety of spatial scales, Glob. Change Biol., 15, 1911-1929, https://doi.org/10.1111/j.1365-2486.2008.01825.x, 2009.

Kohler, K. E. and Gill, S. M.: Coral Point Count with Excel extensions (CPCe): A Visual Basic program for the determination of coral and substrate coverage using random point count methodology, Comput. Geosci., 32, 1259-1269, https://doi.org/10.1016/j.cageo.2005.11.009, 2006.

Kraan, C., van Gils, J. A., Spaans, B., Dekinga, A., Bijleveld, A. I., van Roomen, M., Kleefstra, R., and Piersma, T.: Landscapescale experiment demonstrates that Wadden Sea intertidal flats are used to capacity by molluscivore migrant shorebirds, J. Anim. Ecol., 78, 1259-1268, https://doi.org/10.1111/j.13652656.2009.01564.x, 2009.

Kraan, C., Aarts, G., van der Meer, J., and Piersma, T.: The role of environmental variables in structuring landscape-scale species distributions in seafloor habitats, Ecology, 91, 15831590, https://doi.org/10.1890/09-2040.1, 2010.

Kraan, C., Aarts, G., Piersma, T., and Dormann, C. F.: Temporal variability of ecological niches: a study on intertidal benthic fauna, Oikos, 122, 754-760, https://doi.org/10.1111/j.16000706.2012.20418.x, 2013. 
Kraan, C., Dormann, C. F., Greenfield, B. L., and Thrush, S. F.: Cross-scale variation in biodiversity-environment links illustrated by coastal sandflat communities, PLoS ONE, 10, e0142411, https://doi.org/10.1371/journal.pone.0142411, 2015.

Kraan, C., Greenfield, B. L., and Thrush, S. F.: Multi-scale data on intertidal macrobenthic biodiversity and environmental features in three New Zealand harbours, PANGAEA, https://doi.org/10.1594/PANGAEA.903448, 2019.

Lohrer, A. M., Thrush, S. F., Hewitt, J. E., and Kraan, C.: The upscaling of ecosystem functions in a heterogeneous world, Sci. Rep.-UK, 5, 10349, https://doi.org/10.1038/srep10349, 2015.
Thrush, S. F., Hewitt, J. E., Norkko, A., Nicholls, P. E., Funnell, G. A., and Ellis, J. I.: Habitat change in estuaries: predicting broad-scale responses of intertidal macrofauna to sediment mud content, Mar. Ecol.-Prog. Ser., 263, 101-112, https://doi.org/10.3354/meps263101, 2003.

Thrush, S. F., Hewitt, J. E., Kraan, C., Lohrer, A. M., Pilditch, A. M., and Douglas, E. J.: Changes in the location of biodiversityecosystem function hot spots across the seafloor landscape with increasing sediment nutrient loading, P. Roy. Soc. Lond. B Bio., 284, 20162861, https://doi.org/10.1098/rspb.2016.2861, 2017. 